\title{
Strategi Pengembangan Durian Wonosalam Agrowisata Jombang
}

\author{
Miftachul chusnah ${ }^{1}$, Sumardji ${ }^{2}$, Ahsin Daroini $^{3}$ \\ ${ }^{1}$ Program Studi Agribisnis Pasca Sarjana, Universitas Islam Kadiri, Sersan Suharmaji No.38, Manisrenggo, Kec. Kota Kediri, \\ Kediri, Jawa Timur, 64128 \\ E-mail: miftachuchusnah171@gmail.com \\ ${ }^{2}$ Program Studi Agribisnis Pasca Sarjana, Universitas Islam Kadiri, Sersan Suharmaji No.38, Manisrenggo, Kec. Kota Kediri, \\ Kediri, Jawa Timur, 64128 \\ E-mail: - \\ ${ }^{3}$ Program Studi Agribisnis Pasca Sarjana, Universitas Islam Kadiri, Sersan Suharmaji No.38, Manisrenggo, Kec. Kota Kediri, \\ Kediri, Jawa Timur, 64128 \\ E-mail: -
}

\begin{abstract}
The purpose of this study is to identify the factors that influence and the right strategy in developing the Wonosalam durian agro-tourism area. The location of the study was carried out in the village of Wonosalam, Wonosalam District, Jombang City. This research was conducted for (two) months, namely between February - March 2019. The data used in this study are primary data and secondary data. Primary data is data taken directly from the research location of the Durian Wonosalam agrotourism area through direct observation at the site, interviews with the government, community shops, and filling out questionnaires. Respondents were selected by 20 people to fill out the research questionnaire as follows: Government (3 people), namely the Head of the device and the Office of Tourism Staff of Jombang ( 2 people) Community Stores ( 2 people), Tourist managers (3 people). And Visitors (10 people). Secondary data is data obtained through agencies related to this research, both tabulation and descriptive. The analytical methods used are SWOT and QSPM analysis. Based on the results of the research and discussion, it can be concluded that the alternative strategy for developing the right durian Wonosalam agro-tourism area is the SO Strategy, namely the strategy of agro-tourism development by maintaining the existing tourism power and development strategy by increasing promotion to related parties and outside regions through seminar seminars or utilizing technological developments the highest value of attraction is found in strategy 1 (SO) with total attractiveness (TAS) of 6.164. by exploring the potential and actions of tourism preservation that exist as a characteristic possessed by the Wonosalam region with a variety of attractions that are owned, Optimizing the superiority of tourism remains quality so as to attract tourists.
\end{abstract}

Keywords—: Strategy; development; agrotourism; SWOT; QSPM.

\section{PENDAHULUAN}

Indonesia merupakan negara berkembang di dunia yang saat ini sedang meningkatkan pembangunan di segala bidang mulai dari bidang ekonomi sampai dengan bidang pertanian. Hal ini dapat terlihat dari banyaknya daerah yang menjadi pusat aktivitas dan pertumbuhan penduduk, salah satunya kawasan konsumsi jasa dalam bentuk komoditas wisata pertanian. Konsumsi jasa dalam bentuk komoditas wisata pertanian di Indonesia cenderung mengalami peningkatan yang pesat. Peningkatan ini terlihat dari jumlah kunjungan wisatawan baik mancanegara yang datang ke Indonesia naik 5,22\% dalam 5 bulan pertama tahun 2010 , maupun wisatawan lokal ke Jawa Timur yang naik 1,7\% pada tahun 2008-2009 (Martaleni, 2011).

Kementerian Desa, Pembangunan Daerah Tertinggal dan Transmigrasi (Kemendes PDTT) menyatakan bahwa di Indonesia ada 2.000 Desa Berpotensi Wisata. Di tiap desa wisata akan dibangun 5 homestay, kategori desa wisata bahari mempunyai 787 desa. Kategori Desa Wisata Sungai mempunyai 576 desa, sedangkan desa Wisata Irigasi 165 desa. Sementara Desa Wisata Danau, jumlahnya mencapai 374 desa. "Pendanaan bisa dari dana desa dan desa yang akan menentukan. Menurut Kemendes di tahun depan ada kemungkinan anggaran Kemendes PDTT tahun depan naik dua kali lipat menjadi Rp 120 triliun dari Rp 60 triliun. Dengan demikian, kemungkinan besar tahun depan pembangunan homestay akan lebih banyak lagi. Dibutuhkan pengelolaan secara korporasi bisa melalui BUMDes atau lainnya agar pembangunan homestay ini benar-benar memberikan dampak ekonomi pada desa-desa yang memiliki potensi tersebut. Dan saat ini dana desa yang diberikan ke masing-masing desa sebesar Rp 800 juta. Diharapkan Kemenpar turut memberikan pendampingan dan membantu penjualan untuk desa yang memliki potensi dalam sektor pariwisata. Pariwisata adalah cara yang cepat, mudah, dan murah untuk menghidupkan usaha di desa dengan konsep Homestay Desa Wisata itu. Sementara Kemendes bertanggung jawab untuk menghidupkan ekonomi masyarakat desa. Prioritas penggunaan dana desa, ada semacam pergeseran, dua tahun pertama menyangkut kesiapan atau membangun infrastruktur. Namun bagi desa-desa yang memang memiliki potensi wisata, dana tersebut boleh digunakan untuk membangun infrastruktur untuk mendukung wisatanya, termasuk homestay. Kemendes PDTT juga telah membentuk taskforce dengan melibatkan Kemenpar dan kepala daerah di sejumlah kabupaten. Menurut Menteri Pariwisata Arief Yahya, kolaborasi desa wisata itu bisa dengan cepat direalisasikan. Membangun hotel dan resort kelas dunia, membutuihkan waktu lama, 5 tahun. Tapi membangun homestay, 6 bulan sudah cukup karena itu secara paralel, program pemberdayaan desa menjadi desa wisata itu akan sangat cantik. (CNN Indonesia, 2017) 
Website : http://agritek.unmermadiun.ac.id/index.php/agritek

Melalui pengembangan desa wisata, pariwisata juga terbukti mampu meningkatkan kesejahteraan masyarakat lokal, meningkatkan kepedulian terhadap lingkungan, serta memotivasi masyarakat untuk bangga terhadap identitas kebudayaanya (Hermawan, 2016). Oleh karena itu, sangat tepat jika Pemerintah telah berkomitmen menempatkan kepariwisataan sebagai tulang punggung perekonomian negara, dengan menempatkan pariwisata sebagai prioritas pembangunan Nasional. Kementerian Pariwisata (Kemenpar) menetapkan enam target utama pembangunan pariwisata, diantara yang sangat strategik adalah target peningkatan indeks daya saing pariwisata dari peringkat 70 pada tahun 2014 menjadi 30 pada tahun 2019, sekaligus meningkatkan jumlah kunjungan wisatawan mancanegara (Yahya 2015).

Zhung dan Awan (2016) menegaskan bahwa agrowisata di Cina telah menjadi titik awal dalam menggabungkan pengembangan industri primer dan tersier dan telah menyadari pertumbuhan pesat dalam tiga dekade terakhir pembangunan ekonomi di banyak daerah. Identifikasi masalah-masalah utama berdasarkan pada agrowisata berkelanjutan, prospek manajemen dan kebijakan pariwisata pedesaan Cina. Agritourisme Tiongkok perlu mempertimbangkan keunikan fitur pariwisata berkelanjutan yang instingtif dan harus difokuskan untuk studi lebih lanjut. Wonosalam adalah sebuah kecamatan di Kabupaten Jombang, ProvinsiJawa Timur, Indonesia. Kecamatan ini terletak di kaki dan lereng Gunung Anjasmoro dengan ketinggian rata-rata 500-600 meter di atas permukaan laut. Kecamatan Wonosalam terletak 35 km sebelah tenggara Kecamatan Jombang. Kecamatan Wonosalam adalah salah satu penghasil durian terbesar di Jawa Timur. Selain itu kawasan Wonosalam juga memiliki potensi pariwisata yang besar, khususnya agrowisata karena mayoritas mata pencaharian penduduknya adalah petani. Selain durian, di kawasan Wonosalam juga merupakan penghasil cengkeh, kopi dan pisang. Pusat pemerintahan Kecamatan Wonosalam terletak di Desa Wonosalam, yaitu terletak pada bagian tengah kecamatan ini.(Pemkab, 2018).

Merujuk pada penelitin terdahulu oleh Rinawati, R.(2014) yang telah meneliti bahwa karakteristik dan penilaian pengunjung, Alternatif strategi pengembangan usaha berdasarkan matriks QSPM yaitu meningkatkan kinerja pemasaran dan efektivitas promosi untuk menjaring menjaring pengunjung yang lebih banyak. Hasil Penelitian Bachtiar A.R., dkk. (2015) terhadap persepsi dan strategi pengembangan agrowisata salak yaitu strategi yang paling tepat untuk diprioritaskan berdasarkan hasil analisis QSPM adalah menggali potensi alam yang dimiliki untuk mengoptimalkan keunggulan agrowisata serta tetap menjaga produk bermutu.Sedangkan Fretes, dkk. (2013) yang menganalisis Alternatif Perencanaan dan Pengembangan Industri Pariwisata dengan menggunakan metode SWOT dan metode QSPM (Studi kasus Kecamatan Leitimur Selatan Kota Ambon), strartegi yang harus digunakan adalah strategi pengembangan produk (product development) yang merupakan strategi meningkatkan pengembangan produk pariwisata kecamatan Leitimur Selatan untuk memanfaatkan semua potensi yang dimiliki.

Potensi Agrowisata yang sangat tinggi ini belum sepenuhnya dikembangkan dan dimanfaatkan secara optimal. Untuk itu, perlu dirumuskan langkah-langkah kebijakan yang konkrit dan operasional guna tercapainya kemantapan pengelolaan Objek Agrowisata di era globalisasi dan otonomi daerah. Sesuai dengan keunikan kekayaan spesifik lokasi yang dimiliki, setiap daerah dan setiap objek wisata dapat menentukan sasaran dan bidang garapan pasar yang dapat dituju. Dalam pengembangan Agrowisata dibutuhkan kerjasama sinergis diantara pelaku yang teribat dalam pengelolaan Agrowisata, yaitu masyarakat, swasta dan pemerintah. Dalam rangka meningkatkan kesejahteraan masyarakat di sekitar kawasan agrowisata, maka program pengembangan Agrowisata durian sangatlah sesuai dengan kondisi tersebut. Melalui program pengembangan Agrowisata durian, diharapkan dapat meningkatkan produksi pertanian khususnya durian di kawasan agrowisata. Akan tetapi, kebun-kebun dikelola dengan kurang baik. Padahal, fungsi dari kebun-kebun durian tersebut sebagai penyimpan air yang bisa digunakan untuk memenuhi kebutuhan air khususnya irigasi. Selain itu, meskipun banyak petani yang membudidayakan durian, tidak serta merta program pengembangan agrowisata ini diikuti dan dikelola oleh petani tersebut. Dengan kata lain, program pengembangan agrowisata ini belum bisa menggerakkan para petani durian secara maksimal.

\section{METODE PENELITIAN}

Alur pelaksanaan penelitian ditulis dengan rinci dan jelas. Spesifikasi bahan-bahan harus rinci agar orang lain mendapat informasi tentang cara memperoleh bahan tersebut. Jika metode yang digunakan telah diketahui sebelumnya, maka acuan pustakanya harus dicantumkan. Jika penelitian terdiri dari beberapa eksperimen, maka metode untuk masing-masing eksperimen dijelaskan pula. Penelitian ini menggunakan metode deskriptif dengan pendekatan kualitatif. Bodgan dan Taylor dalam Moleong (2005) berpendapat bahwa metode kualitatif adalah prosedur penelitian yang menghasilkan data deskriptif berupa kata kata tertulis atau lisan dari orang-orang dan perilaku yang dapat diamati. Pengumpulandata dengan cara : 1. Observasi (pengamatan) yaitu cara untuk memperoleh data dengan jalan mengadakan pengamatan secara langsung mengenai data yang di selidiki. 2. Interview (Wawancara), yaitu dengan teknik pengumpulan data dengan menggunakan tanya jawab. Teknik pengumpulan data ini juga digunakan untuk melengkapi apabila ada jawaban responden terhadap kuisioner yang di berikan kurang jelas. 3. Kuisioner, yaitu teknik pengumpulan data dengan mempergunakan daftar pertanyaan. Pengisian kuesioer untuk tujuan analisis faktor internal dan eksternal, juga penentuan strategi pengembangan kawasan agrowisata durian dengan memilih responden yang memiliki kontribusi besar terhadap perumusan dan pelaksanaan strategi di kawasan agrowisata. Metode pengambilan sampel yang digunakan yaitu purposive sampling. Teknik purposive sampling terjadi ketika peneliti memilih sampel didasarkan pada beberapa kriteria (Cooper dan Schindler, 2006). Responden yang dipilih 20 orang untuk mengisi kuesioner penelitian sebagai berikut : a. Pemerintah ( 5 orang), yaitu kepala desa dan perangkat desa (3) dan Pegawai Dinas Pariwisata Kota Jombnag (2). b. Tokoh Masyarakat (2 orang) c. Pengelola objek wisata ( 3 orang) dan d. Pengunjung (10 orang). Data skunder diperoleh dari instansi dan pustaka yang dapat menunjang penelitian 
Website : http://agritek.unmermadiun.ac.id/index.php/agritek

Metode analisis yang digunakan dalam mengidentifikasi strategi pengembangan kawasan agrowisata durian Wonosalam adalah dengan menggunakan Analisis SWOT. Menurut Rangkuti (2015), Analisis SWOT yaitu membandingkan antara faktor eksternal peluang (opportunities) dan ancaman (threats) dengan faktor internal kekuatan (strengths), dan kelemahan (weaknesses). Sedangkan menurut Menurut (David Freed. R 2009:30) analisis SWOT adalah identfikasi faktor internal dan faktor eksternal perusahaan yang secara sistematis untuk merumuskan strategi perusahaan. Matriks SWOT Menurut (Irham Fahmi 2013:270), Alat yang digunakan untuk menyusun faktor faktor strategi perusahaan adalah matrik SWOT. Matrik ini dapat menggambarkan dengan jelas bagaimana peluang dan ancaman eksternal yang dihadapi perusahaan dapat disesuaikan dengan kekuatan dan kelemahan yang dimilikinya. Matriks SWOT dipilih karena cepat, efektif dan efisien dalam menemukan kemungkinan kemungkinan yang berkaitan dengan pengembangan. (Putri, N.E., 2014)

\section{A. Analisis faktor-faktor strategis internal dan ekstemal (IFAS - EFAS).}

Analisis faktor strategi internal dan ekstemal adalah pengolahan faktor-faktor strategis pada lingkungan intemal dan ekstemal dengan memberikan pembobotan dan rating pada setiap faktor srtategis. Menganalisis Iingkungan internal (IFAS) untuk mengetahui berbagai kemungkinan kekuatan dan kelemahan. Masalah strategis yang akan dimonitor harus ditentukan karena masalah mungkin dapatmempengaruhi pariwisata dimasa yang akan datang. Menganalisis lingkungan eksternal (EFAS) untuk mengetahui berbagai kemungkinan peluang dan ancaman. Masalah strategis yang akan dimonitor harus ditentukan karena masalah ini mungkin dapat mempengaruhi pariwisata dimasa yang akan dating.

\section{B. Pemetaan Posisi Pariwisata}

Pemetaan posisi pariwisata bertujuan untuk mengetahui posisi pariwísata dari suatu objek wisata dalam kondisi perkembangannya saat ini. Pemetaan didasarkan pada analogi sifat yang dimiliki dari faktor-faktor strategis. Kekuatan memiliki sifat positif, kelemahan bersifat negatif, begitu juga dengan peluang bersifat positif dan ancaman bersifat negatif

Diagram posisi perkembangan pariwisata memberikang ambaran keadaan perkembangan pariwisata berdasarkan kuadrankuadran yang dihasilkan garis Vektor SW dan garis Vektor OT, setiap kuadran memiliki rumusan strategi sebagai strategi utamanya. Seperti lelah dijelaskan sebelumnya garis Vektor pada diagram posisi perkembangan pariwisata didasarkan pada logika faktor strategi internal membentuk garis horisontal dan faktor strategi ekstemal membentuk garis vertikal. Rumusan setiap kuadran yang secara khusus untuk pariwisata dan beberapa pengertian yang melalui proses adopsi, adaptasi dari penggunaan analisis SWOT untuk perusahaan, sehingga diadaptasi satu rumusan sebagai berikut : 1) Kuadran I : Growth (perlumbuhan), 2) Kuadran Il : Stability. 3) Kuadran 111 : Survival (Bertahan) dan 4) Kuadran IV : Diversifkasi.

Alternative strategi merupakan hasil matrik analisis SWOT yang menghasilkan berupa strategi SO, WO, ST, dan WT. Alternative strategi yang dihasilkan minimal 4 (empat) strategi sebagai hasil dari analisis matrîk SWOT. 1. Strategi SO, strategi ini dibuat berdasarkan jalan pikiran memanfaatkan seluruh kekuatan untuk merebut dan memanfaatkan peluang sebesar besamya. 2. Strategi ST, strategi dalam menggunakan kekuatan yang dimiliki untuk mengatasi ancaman. 3. Strategi WO, diterapkan berdasarkan pemanfaatan peluang yang ada dengan cara meminimalkan kelemahan yang ada. 4. Strategi WT, didasarkan pada kegiatan usaha meminimalkan kelemahan yang ada serta menghindari ancaman atau perkembangan yang tidak menguntungkan diluar perusahaan.

\section{Analisa QSPM}

Quantitative Strategic Planning Matrix (QSPM) merupakan alat analisis dalam pengambilan keputusan. Analisis QSPM memungkinkan perusahaan untuk mengevaluasi alternatif strategi secara objektif, berdasarkan faktor internal dan eksternal yang telah diidentifikasi sebelumnya. Matriks ini digunakan untuk mengevaluasi dan memilih strategi terbaik yang paling sesuai dengan lingkungan eksternal dan internal. Penentuan alternatif strategi yang memiliki nilai total terbesar pada matriks QSPM merupakan strategi yang paling baik (Prastiti, 2012).

\section{III.HASIL DAN PEMBAHASAN}

\section{A. KondisiAlamKecamatanWonosalam}

Daerah yang dijadikan obyek penelitian adalah kecamatan Wonosalam kabupaten Jombang. Kecamatan Wonosalam merupakan kecamatan dengan luas wilayah 13.904,951 Ha, ketinggian wilayah $90 \mathrm{dpl}$, suhu maksimum/minimum $30 \mathrm{c} / 23 \mathrm{c}$, jumlah hari dengan curah hujan terbanyak 93 hari, banyaknya curah hujan $2239 \mathrm{~mm} / \mathrm{thn}$, jarak dengan kabupaten/kota $25 \mathrm{~km}$ 0,5 jam,jarak dengan ibu kota propinsi $80 \mathrm{~km} 2$ jam.

Desa Wonosalam merupakan salah satu desa yang terletak di Kecamatan Wonosalam Secara umum karakteristik wilayah desa Wonosalam dapat dilihat dari aspek fisik yang meliputi letak, luas, topografi dan kondisi iklim. Desa Wonosalam merupakan Desa yang terletak $\pm 1 \mathrm{Km}$ dari pusat Pemerintahan Kecamatan Wonosalam Secara administrative batas - batas desa Wonosalam adalah sebagai berikut : sebelah utara adalah desa Wonokerto Kec. Wonosalam, sebelah Selatan desa Sambirejo Kec. Wonosalam, sebelah barat desa Pulosari Kec. Bareng, sebelah timur desa Carangwulung Kec. Wonosalam

\section{B. Analisa SWOT}


Website : http://agritek.unmermadiun.ac.id/index.php/agritek

Metode analisis yang digunakan dalam mengidentifikasi strategi pengembangan kawasan agrowisata durian Wonosalam adalah dengan menggunakan Analisis SWOT

a) Analisisfaktor-faktorinternal dan ekstemal (IFAS - EFAS).

Analisis lingkungan internal yang dilakukan yaitu terhadap faktor-faktor strategis internal yang terdiri dari kekuatan dan kelemahan. Analisis faktor strategi internal dan ekstemal adalah pengolahan faktor-faktor strategis pada lingkungan intemal dan ekstemal dengan memberikan pembobotan dan rating pada setiap faktor srtategis. Menganalisis Iingkungan internal (IFAS) untuk mengetahui berbagai kemungkinan kekuatan dan kelemahan. Masalah strategis yang akan dimonitor harus ditentukan karena masalah mungkin dapatmempengaruhi pariwisata dimasa yang akan datang. Menganalisis lingkungan eksternal (EFAS) untuk mengetahui berbagai kemungkinan peluang dan ancaman. Masalah strategis yang akan dimonitor harus ditentukan karena masalah ini mungkin dapat mempengaruhi pariwisata dimasa yang akan dating.

Tabel 1. Matrik IFAS

\begin{tabular}{|c|c|c|c|}
\hline Uraian & Bobot & Rating & Skor \\
\hline \multicolumn{4}{|l|}{ Kekuatan (Strenght) } \\
\hline $\begin{array}{l}\text { 1. Keindahan dan lingkungan alam yang sejuk di lereng gunung } \\
\text { Anjasmoro }\end{array}$ & 0,105 & 4 & 0,42 \\
\hline 2.. Wisata petik Durian Wonosalam/kampung durian & 0,103 & 4 & 0,412 \\
\hline $\begin{array}{l}\text { 3. Adanya wisata kuliner khasWonosalam (Kolak ketan durian yang } \\
\text { terkenal legit) }\end{array}$ & 0,103 & 4 & 0,412 \\
\hline $\begin{array}{l}\text { 4.. Diadakannya wisata kenduri Durian tiap tahun yang banyak menarik } \\
\text { pengunjung }\end{array}$ & 0,11 & 4 & 0,44 \\
\hline $\begin{array}{l}\text { 5. Tumbuhnya kegiatan ekonomi kreatif masyarakat setempat.untuk } \\
\text { meningkatkan pendapatan }\end{array}$ & 0,09 & 3 & 0,27 \\
\hline 6. Lokasi yang strategis tidak terlalu jauh dari kota & 0,084 & 3 & 0,257 \\
\hline 7. Sikap masyarakat yang ramah dan mendukung wisata & 0,077 & 3 & 0,231 \\
\hline $\begin{array}{l}\text { 8. Banyaknya destinasi wisata lain di daerah Wonosalam (air terjun, Goa } \\
\text { goa, Makam, Agrowisata (Pangklungan, gunung Kuncung dll. }\end{array}$ & 0,084 & 3 & 0,252 \\
\hline $\begin{array}{l}\text { 9. Penanganan pasca panen durian : sortasi dan grading, olahan jenang } \\
\text { durian, pengemasan buah durian dengan plastik mika) Penanganan } \\
\text { pasca panen durian : sortasi dan grading, olahan jenang durian, } \\
\text { pengemasan buah durian dengan plastik mika) }\end{array}$ & 0,053 & 2 & 0,106 \\
\hline $\begin{array}{l}10 \text { Pemanfaatan limbah durian : kulit durian sebagai bahan baku briket, } \\
\text { isi durian untuk bahan campuran tempe dan penstabil es krim susu }\end{array}$ & 0.056 & 2 & 0,112 \\
\hline Jumlah & 0,865 & & 2.912 \\
\hline \multicolumn{4}{|l|}{ Kelemahan (Weak) } \\
\hline $\begin{array}{l}\text { Sarana dan prasarana yang kurang memadai.(Jalan yang kurang lebar dan } \\
\text { kurangnya area parkir) }\end{array}$ & 0,04 & 1 & 0,04 \\
\hline Kurangnya layanan informasi kepariwisataan & 0,056 & 2 & 0,112 \\
\hline Pengelolaan dan pelaku objek wisata belum maksimal & 0,04 & 1 & 0,04 \\
\hline Jumlah & 0,136 & & 0,192 \\
\hline Jumlah total & 1 & & 3,104 \\
\hline Kekuatan - Kelemahan $=2,912-0,192=2,72$ & & & \\
\hline
\end{tabular}

Berdasarkan tabel 1 menunjukan bahwa faktor-faktor strategi internal memiliki nilai yang berbeda-beda. Faktor kekuatan terpenting pertama adalah diadakannya pesta kenduri durian tiap tahun yang memperoleh skor 0,44 . Faktor ini merupakan hal paling sangat berpengaruh terhadap pengembangan agrowisata durian Wonosalam, acara ini diadakan setiap tahun sebagai rasa syukur masyarakat Wonosalam dengan hasil alam yang melimpah yang menarik banyak pengunjung dan masyarakat luar sangat antusias mendatangi acara ini, bahkan dari Jakarta dengan memilih datang lebih dulu tinggal di Villa

Tabel 2. Matrik EFAS

\begin{tabular}{|c|c|c|c|}
\hline Uraian & Bobot & Rating & Skor \\
\hline \multicolumn{4}{|l|}{ Peluang (Opportunity) } \\
\hline 1.Adanya kunjungan banyak wisatawan & 0,08 & 3 & 0,24 \\
\hline 2. Letak strategis terhadap objek wisata lain & 0,08 & 3 & 0,24 \\
\hline 3. Adanya kepastian hukum terbukti sebagai daerah wisata & 0,1 & 4 & 0,40 \\
\hline 4 Adanya kebijakan pemda & 0,097 & 4 & 0,388 \\
\hline $\begin{array}{l}5 \text { Adanya kecenderungan penerapan konsep multi fungsi lahan pertanian, sebagai } \\
\text { areal produksi pertanian dan objek wisata Lahan pertanian yang unik } \\
\text { berpeluang besar untuk di multifungsikan. }\end{array}$ & 0,07 & 3 & 0,21 \\
\hline 6 Kebutuhan akan destinasi wisata alternatif.. & 0,096 & 4 & 0,384 \\
\hline 7.Terjalinnya kerjasama pemerintah, investor, dan masyarakat & 0,08 & 3 & 0,24 \\
\hline 8. Otonomi daerah yang diberlakukan pemerintah. & 0,072 & 3 & 0,216 \\
\hline 9. Adanya promosi wisata lewat media & 0,08 & 3 & 0,24 \\
\hline 10. Nilai budaya masyarakat setempat telah mengakar di masyarakat seperti gotong & 0,08 & 3 & 0,24 \\
\hline
\end{tabular}


Website : http://agritek.unmermadiun.ac.id/index.php/agritek

\begin{tabular}{|c|c|c|c|}
\hline royong, kepercayaan, bahasa, adat istiadat, dan lain sebagainya. & & & \\
\hline Jumlah & 0,836 & & 2,798 \\
\hline \multicolumn{4}{|l|}{ Ancaman (Threat) } \\
\hline $\begin{array}{l}\text { 1. Persaingan dengan daerah lain dalam pengembangan desa wisata.(Kenduri Salak } \\
\text { Di Wonosalam dan kediri) }\end{array}$ & 0,026 & 1 & 0,026 \\
\hline 2. Berubahnya pola pikir dan perilaku masyarakat. & 0,05 & 2 & 0,10 \\
\hline 3. Adanya pedagang dari luar Wonosalam & 0,035 & 1 & 0,035 \\
\hline 4. Adanya penduduk pendatang. & 0,053 & 2 & 0,106 \\
\hline Jumlah & 0,164 & & 0,267 \\
\hline Jumlah total & 1,00 & & 2,665 \\
\hline Peluang - Ancaman $=2,798-0,267=2,531$ & & & \\
\hline
\end{tabular}

Berdasarkan tabel 2 hasil perhitungan matriks EFE (External Factors Evaluation) faktor eksternal yang menjadi peluang terbesar bagi pengembangan agrowisata durian Wonosalam adalah kepastian hukuam sebagai daerah wisata dengan skor sebesar 0,44. Kecamatan Wonosalam memiliki potensi dalam pengembangan agrowisata dengan memiliki panorama yang indah, Hal ini disebabkan daerah Wonosalam berupa perbukitan serta memiliki berbagai jenis tanaman yang dibudidayakan seperti kakao, cengkeh, melinjo, dan durian. Sebagaimana di atur dalam Keputusan Bupati Jombang Nomor: 188.4.45/189/415.10.10/2010 tentang Penetapan Kawasan Agropolitan pada Satuan Kawasan Pengembangan Pertanian (SKPP) Kabupaten Jombang, Kecamatan Wonosalam ditetapkan sebagai lokasi dan komoditas unggul dalam kawasan agropolitan.

Sedangkan faktor eksternal yang menjadi ancaman terbesar bagi pengembangan agrowisata durian Wonosalam adalah persaingan dengan daerah lain sebagai daerah wisata dengan skor sebesar 0,026. Masing masing daerah biasanya memiliki daya wisata sesuai dengan kondisi alamnya, dengan hasil panen yang melimpah maka masyarakat yang telah sadar wisata juga ingin mengembangkan daya wisata daerahnya dengan terinspirasi adanya kenduri durian, diadakanlah kenduri salak di Wonosalam dan kenduri manggis di desa Jarak., karena ini akan mempengaruhi daya wisata kenduri durian, sehingga harus ada peningkatan dan pengembangan agar masyarakat luar tetap antusias dengan kenduri durian, dengan banyaknya acara sebelum kenduri durian ini akan mempertahankan daya wisata kenduri durian. Hasil analisis matriks EFE untuk peluang dan ancaman diperoleh total skor faktor eksternal sebesar 2,665, hal ini menujukkan pengembangan agrowisata durian Wonosalam masih mampu mengatasi ancaman yang mungkin akan terjadi.

Pemetaan Posisi Pariwisata

Pemetaan posisi pariwisata bertujuan untuk mengetahui posisi pariwísata dari suatu objek wisata dalam kondisi perkembangannya saat ini. Pemetaan didasarkan pada analogi sifat yang dimiliki dari faktor-faktor strategis. Kekuatan memiliki sifat positif, kelemahan bersifat negatif, begitu juga dengan peluang bersifat positif

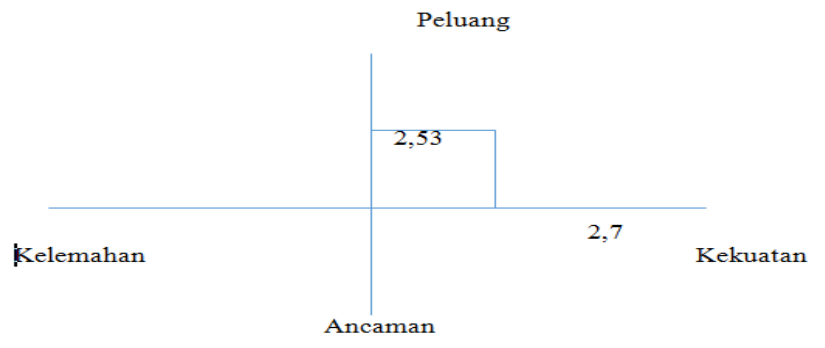

Pemetaan terhadap masing-masing total skor dari faktor-faktor internal dan eksternal menggambarkan posisi pengembangan agrowisata durian Wonosalam, saat ini berada pada kuadran I dalam matriks IE. Growth (perlumbuhan) strategi pertumbuhan dirumuskan untuk mencapai pertumbuhan, penjualan, aset, proñt atau kombinasi ketiganya (Rangkuti, 2015). Pertumbuhan dalam pariwisata adalah pertumbuhan jumlah kunjungan wisatawan (frekuensi kunjungan dan asal daerah wisatawan), aset (objek dan daya tarik wisata, prasarana dan sarana pendukung), pendapatan (retribusi masuk dan jumlah yang dibelanjakan).

\section{MatrikSwot}

Alternative strategi merupakan hasil matrik analisis SWOT yang menghasilkan berupa strategi SO, WO, ST, dan WT. Alternative strategi yang dihasilkan minimal 4 (empat) strategi sebagai hasil dari analisis matrîk SWOT. 1. Strategi SO, strategi ini dibuat berdasarkan jalan pikiran memanfaatkan seluruh kekuatan untuk merebut dan memanfaatkan peluang sebesar besamya. 2. Strategi ST, strategi dalam menggunakan kekuatan yang dimiliki untuk mengatasi ancaman. 3. Strategi WO, diterapkan berdasarkan pemanfaatan peluang yang ada dengan cara meminimalkan kelemahan yang ada. 4. Strategi WT, 
Website : http://agritek.unmermadiun.ac.id/index.php/agritek

didasarkan pada kegiatan usaha meminimalkan kelemahan yang ada serta menghindari ancaman atau perkembangan yang tidak menguntungkan diluar perusahaan.

\begin{tabular}{|c|c|c|}
\hline $\begin{array}{l}\text { IFAS } \\
\text { EFAS }\end{array}$ & $\begin{array}{l}\text { STRENGTHS (S) } \\
\text { 1.Keindahan dan lingkungan alam yang sejuk } \\
\text { di lereng gunung Anjasmoro } \\
\text { 2. WisatapetikDurianWonosalam/kampung } \\
\text { durian } \\
\text { 3.Adanyawisatakuliner khasWonosalam } \\
\text { (Kolak ketan durian yang terkenal legit) } \\
\text { 4. Diadakannya wisata kenduri Durian tiap } \\
\text { tahun yang banyak menarik pengunjung } \\
\text { 5. Tumbuhnya kegiatan ekonomi kreatif } \\
\text { masyarakat setempat.untuk meningkatkan } \\
\text { pendapatan } \\
\text { 6 Lokasi yang strategis tidak terlalu jauh dari } \\
\text { kota } \\
\text { 7.Sikap masyarakat yang ramah dan } \\
\text { mendukung wisata } \\
\text { 8. Banyaknya destinasi wisata lain di daerah } \\
\text { Wonosalam (air terjun, Goa goa, Makam, } \\
\text { Agrowisata (Pangklungan, gunung } \\
\text { Kuncung dll. } \\
\text { 9. Penanganan pasca panen durian : sortasi } \\
\text { dan grading, olahan jenang durian, } \\
\text { pengemasan buah durian dengan plastik } \\
\text { mika) Penanganan pasca panen durian : } \\
\text { sortasi dan grading, olahan jenang durian, } \\
\text { pengemasan buah durian dengan plastik } \\
\text { mika) } \\
\text { 10. Pemanfaatan limbah durian : kulit durian } \\
\text { sebagai bahan baku briket, isi durian untuk } \\
\text { bahan campuran tempe dan penstabil es } \\
\text { krim susu }\end{array}$ & $\begin{array}{l}\text { WEAKNESSES (W) } \\
\text { 1.Sarana dan prasarana yang kurang } \\
\text { memadai.(Jalan yang kurang lebar dan } \\
\text { kurangnya area parkir) } \\
\text { 2. Kurangnya layanan informasi } \\
\text { kepariwisataan } \\
\text { 3. Pengelolaan dan pelaku objek wisata } \\
\text { belum maksimal }\end{array}$ \\
\hline $\begin{array}{l}\text { OPPORTUNIES (O) } \\
\text { 1.Adanya kunjungan banyak } \\
\text { wisatawan } \\
\text { 2. Letak strategis terhadap objek } \\
\text { wisata lain } \\
\text { 3. Adanya kepastian hukum } \\
\text { terbukti sebagai daerah wisata } \\
\text { 4. Adanya kebijakan pemda } \\
\text { 5. Adanya kecenderungan } \\
\text { penerapan konsep multi } \\
\text { fungsi lahan pertanian, } \\
\text { sebagai areal produksi } \\
\text { pertanian dan objek wisata } \\
\text { Lahan pertanian yang unik } \\
\text { berpeluang besar untuk di } \\
\text { multifungsikan. } \\
\text { Kebutuhan akan destinasi } \\
\text { wisata alternatif. } \\
\text { Terjalinnya kerjasama } \\
\text { pemerintah, investor, dan } \\
\text { masyarakat daerah yang } \\
\text { Otonomi daerah } \\
\text { diberlakukan pemerintah } \\
\text { 9. Adanya promosi wisata lewat } \\
\text { media } \\
\text { Nilai budaya masyarakat } \\
\text { setempat telah mengakar di } \\
\text { masyarakat seperti gotong } \\
\text { royong, kepercayaan, bahasa, } \\
\text { adat istiadat, dan lain } \\
\text { sebagainya. }\end{array}$ & $\begin{array}{l}\text { STRATEGI SO } \\
\text { Strategi Pengembangan agrowisata dengan } \\
\text { mempertahankan berbagai daya tarik Wisata } \\
\text { Strategi pengembangan dengan melakukan } \\
\text { promosi ke pihak pihak terkait dan ke daerah } \\
\text { luar baik melaui seminar, pameran ataupun } \\
\text { dengan memanfaatkan perkembangan } \\
\text { teknologi }\end{array}$ & $\begin{array}{l}\text { STRATEGI WO } \\
\text { Strategi Peningkatan Sarana dan Prasarana } \\
\text { Pendukung Pengembangan agrowisata } \\
\text { unbtuk meningkatkan jumlah pengunjung }\end{array}$ \\
\hline
\end{tabular}


Website : http://agritek.unmermadiun.ac.id/index.php/agritek

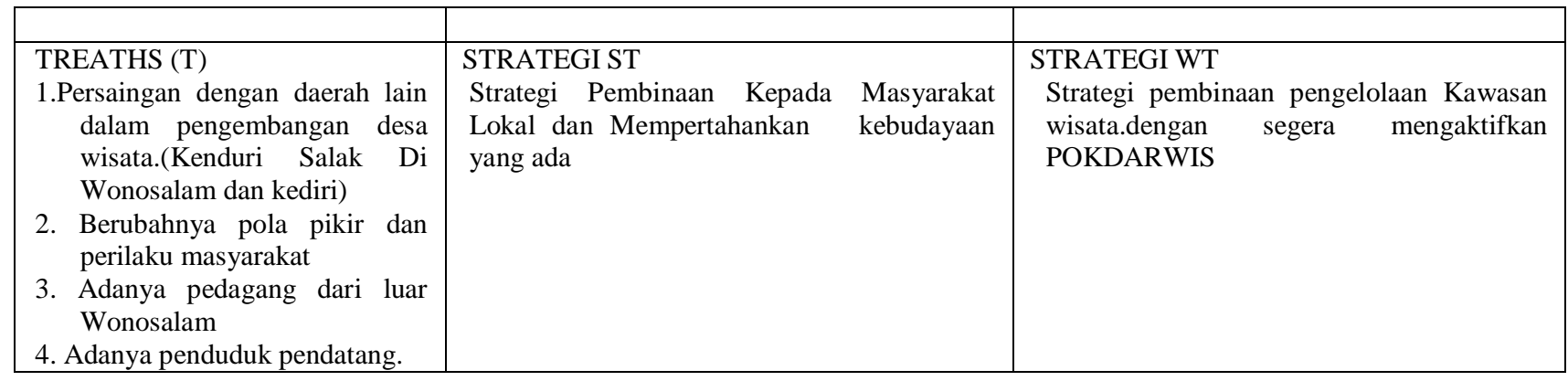

Berdasarkan Tabel 3, strategi yang menggunakan S-O adalah strategi yang memanfaatkan seluruh kekuatan untuk merebut dan memanfaatkan peluang sebesar besarnya. Strategi yang perlu dilakukan adalah strategi pengembangan desa wisata, mempertahankan daya tarik yang ada dan Strategi pengembangan dengan melakukan promosi ke pihak pihak terkait dan ke daerah luar baik melaui seminar, pameran ataupun dengan memanfaatkan perkembangan teknologi. Strategi pengembangan desa wisata dilakukan dengan mempertahankan daya tarik wisata yang ada di daerah Wonosalam, yaitu dengan tindakan pelestarian wisata yang ada sebagai ciri khas yang dimiliki oleh daerah Wonosalam dengan beranekaragam daya tarik yang dimiliki sehingga menarik wisatawan seperti macam macam destinasi wisata, acara kenduri durian, kampung/petik durian, dan kuliner kolak ketan durian.

\section{AnalisaQSPM}

Metode QSPM adalah suatu alat untuk mengevaluasi pilihan alternatif secara objektif, menetapkan daya tarik relatif dari strategi alternatif yang layak dan menentukan strategi yang terbaik (Siahaan, 2008). QSPM mengevaluasi kemenarikan relatif dari beberapa pilihan alternatif strategi secara objektif (Bhandari and Verna, 2013; Umar, 2011). Sedangkan menurut David (2009), Quantitative Strategic Planning Matrix (QSPM) merupakan alat analisis dalam pengambilan keputusan. Analisis QSPM memungkinkan perusahaan untuk mengevaluasi alternatif strategi secara objektif, berdasarkan faktor internal dan eksternal yang telah diidentifikasi sebelumnya. Matriks ini digunakan untuk mengevaluasi dan memilih strategi terbaik yang paling sesuai dengan lingkungan eksternal dan internal. Penentuan alternatif strategi yang memiliki nilai total terbesar pada matriks QSPM merupakan strategi yang paling baik (Prastiti, 2012).

Tabel 4.MatrikQSPM Pengembangan Agrowisata Durian Wonosalam.

\begin{tabular}{|c|c|c|c|c|c|c|c|c|c|c|}
\hline \multirow{2}{*}{ No } & \multirow{2}{*}{ Faktor Faktor } & \multicolumn{9}{|c|}{ Alternatif Strategi } \\
\hline & & Bobot & AS & TAS & AS & TAS & AS & TAS & AS & TAS \\
\hline & Kekuatan & & & & & & & & & \\
\hline 1 & $\begin{array}{l}\text { Keindahan dan lingkungan alam yang sejuk di } \\
\text { lereng gunung Anjasmoro }\end{array}$ & 0,105 & 3 & 0,315 & 4 & 0,424 & 1 & 0,105 & 1 & 0,105 \\
\hline 2 & WisatapetikDurianWonosalam/kampung durian & 0,103 & 4 & 0,412 & 4 & 0,412 & 1 & 0,103 & 3 & 0,309 \\
\hline 3 & $\begin{array}{l}\text { Adanyawisatakuliner khasWonosalam (Kolak } \\
\text { ketan durian yang terkenal legit) }\end{array}$ & 0,103 & 3 & 0,309 & 3 & 0,409 & 2 & 0,206 & 2 & 0,206 \\
\hline 4 & $\begin{array}{l}\text { Diadakannya wisata kenduri Durian tiap tahun } \\
\text { yang banyak menarik pengunjung }\end{array}$ & 0,11 & 4 & 0,44 & 4 & 0,44 & 3 & 0,33 & 3 & 0,33 \\
\hline 5 & $\begin{array}{l}\text { Tumbuhnya kegiatan ekonomi kreatif } \\
\text { masyarakat setempat.untuk meningkatkan } \\
\text { pendapatan }\end{array}$ & 0,09 & 3 & 0,27 & 3 & 0,27 & 3 & 0,27 & 2 & 0,18 \\
\hline 6 & Lokasi yang strategis tidak terlalu jauh dari kota & 0,084 & 3 & 0,252 & 3 & 0,252 & 2 & 0,168 & 1 & 0,084 \\
\hline 7 & $\begin{array}{l}\text { Sikap masyarakat yang ramah dan mendukung } \\
\text { wisata }\end{array}$ & 0,077 & 3 & 0,231 & 2 & 0,154 & 3 & 0,231 & 2 & 0,154 \\
\hline 8 & $\begin{array}{l}\text { Banyaknya destinasi wisata lain di daerah } \\
\text { Wonosalam (air terjun, Goa goa, Makam, } \\
\text { Agrowisata (Pangklungan, gunung Kuncung dll. }\end{array}$ & 0,084 & 3 & 0,252 & 3 & 0,252 & 3 & 0,252 & 3 & 0,262 \\
\hline 9 & $\begin{array}{l}\text { Penanganan pasca panen durian : sortasi dan } \\
\text { grading, olahan jenang durian, pengemasan buah } \\
\text { durian dengan plastik mika) Penanganan pasca } \\
\text { panen durian : sortasi dan grading, olahan jenang } \\
\text { durian, pengemasan buah durian dengan plastik }\end{array}$ & 0,053 & 2 & 0,106 & 1 & 0,053 & 1 & 0,053 & 1 & 0,053 \\
\hline
\end{tabular}


Website : http://agritek.unmermadiun.ac.id/index.php/agritek

\begin{tabular}{|c|c|c|c|c|c|c|c|c|c|c|}
\hline & mika) & & & & & & & & & \\
\hline \multirow[t]{2}{*}{10} & $\begin{array}{l}\text { Pemanfaatan limbah durian : kulit durian sebagai } \\
\text { bahan baku briket, isi durian untuk bahan } \\
\text { campuran tempe dan penstabil es krim susu }\end{array}$ & 0,056 & 2 & 0,112 & 1 & 0,056 & 1 & 0,056 & 1 & 0,056 \\
\hline & Kelemahan & & & & & & & & & \\
\hline 1 & $\begin{array}{l}\text { Sarana dan prasarana yang kurang } \\
\text { memadai.(Jalan yang kurang lebar dan } \\
\text { kurangnya area parkir) }\end{array}$ & 0,04 & 4 & 0,16 & 4 & 0,16 & 2 & 0,08 & 2 & 0,08 \\
\hline 2 & Kurangnya layanan informasi kepariwisataan & 0,056 & 4 & 0,224 & 4 & 0,224 & 2 & 0,112 & 2 & 0,112 \\
\hline \multirow[t]{2}{*}{3} & $\begin{array}{l}\text { Pengelolaan dan pelaku objek wisata belum } \\
\text { maksimal }\end{array}$ & 0,04 & 3 & 0,12 & 4 & 0,16 & 4 & 0,16 & 4 & 0,16 \\
\hline & Peluang & & & & & & & & & \\
\hline 1 & Adanya kunjungan banyak wisatawan & 0,08 & 4 & 0,32 & 4 & 0,32 & 4 & 0,32 & 4 & 0,32 \\
\hline 2 & Letak strategis terhadap objek wisata lain & 0,08 & 4 & 0,32 & 3 & 0,24 & 2 & 0,16 & 2 & 0,16 \\
\hline 3 & $\begin{array}{l}\text { Adanya kepastian hukum terbukti sebagai daerah } \\
\text { wisata }\end{array}$ & 0,1 & 3 & 0,3 & 3 & 0,3 & 3 & 0,3 & 3 & 0,3 \\
\hline 4 & Adanya kebijakan pemda & 0,097 & 3 & 0,291 & 2 & 0,194 & 3 & 0,291 & 3 & 0,291 \\
\hline 5 & $\begin{array}{l}\text { Adanya kecenderungan penerapan konsep multi } \\
\text { fungsi lahan pertanian, sebagai areal produksi } \\
\text { pertanian dan objek wisata Lahan pertanian yang } \\
\text { unik berpeluang besar untuk di multifungsikan. }\end{array}$ & 0,07 & 2 & 0,14 & 3 & 0,21 & 3 & 0,21 & 3 & 0,21 \\
\hline 6 & Kebutuhan akan destinasi wisata alternatif. & 0,096 & 4 & 0,384 & 2 & 0,192 & 3 & 0,288 & 3 & 0,288 \\
\hline 7 & $\begin{array}{l}\text { Terjalinnya kerjasama pemerintah, investor, dan } \\
\text { masyarakat }\end{array}$ & 0,08 & 4 & 0,32 & 3 & 0,24 & 2 & 0,16 & 2 & 0,16 \\
\hline 8 & Otonomi daerah yang diberlakukan pemerintah & 0,072 & 3 & 0,216 & 4 & 0,288 & 3 & 0,216 & 3 & 0,216 \\
\hline 9 & Adanya promosi wisata lewat media & 0,08 & 3 & 0,24 & 2 & 0,16 & 2 & 0,16 & 3 & 0,24 \\
\hline \multirow[t]{2}{*}{10} & $\begin{array}{l}\text { Nilai budaya masyarakat setempat telah } \\
\text { mengakar di masyarakat seperti gotong royong, } \\
\text { kepercayaan, bahasa, adat istiadat, dan lain } \\
\text { sebagainya }\end{array}$ & 0,08 & 3 & 0,24 & 3 & 0,24 & 4 & 0,32 & 4 & 0,32 \\
\hline & Ancaman & & & & & & & & & \\
\hline 1 & $\begin{array}{l}\text { Persaingan dengan daerah lain dalam } \\
\text { pengembangan desa wisata.(Kenduri Salak Di } \\
\text { Wonosalam dan kediri) }\end{array}$ & 0,026 & 2 & 0,052 & 1 & 0,026 & 4 & 0,104 & 4 & 0,104 \\
\hline 2 & Berubahnya pola pikir dan perilaku masyarakat & 0,05 & 1 & 0,05 & 2 & 0,10 & 4 & 0,2 & 2 & 0,1 \\
\hline 3 & Adanya pedagang dari luar Wonosalam & 0,035 & 1 & 0,035 & 1 & 0,035 & 3 & 0,105 & 3 & 0,105 \\
\hline \multirow[t]{2}{*}{4} & Adanya penduduk pendatang & 0,053 & 1 & 0,053 & 2 & 0,106 & 4 & 0,212 & 4 & 0,212 \\
\hline & Total & & & 6,164 & & 5,817 & & 4,956 & & 5,107 \\
\hline
\end{tabular}

Sumber : Data diolah (2019)

Berdasarkan hasil matriks QSPM, nilai daya tarik tertinggi terdapat pada strategi 1 (SO) dengan jumlah total daya tarik (TAS) sebesar 6,164. Nilai daya tarik tertinggi kedua terdapat pada strategi 2 (WO) dengan jumlah TAS sebesar 5,817, tertinggi ketiga terdapat pada strategi 4 dengan total TAS sebesar 4,956. Sedangkan nilai daya tarik terendah terdapat pada strategi 3 dengan total TAS sebesar 4,956. Strategi-strategi yang dapat didahulukan dalam penerapan strategi pengembangan agrowisata durian Wonosalam dapat dirumuskan dengan urutan strategi sebagai berikut: Strategi SO yaitu : a. Strategi pengembangan agrowisata dengan mempertahankan daya wisata yang ada $b$. Strategi pengembangan dengan meningkatkan promosi ke pihak pihak terkait dan daerah luar melalui seminar seminar atau memanfaatkan perkembangan teknologi.

\section{IV.KESIMPULAN}

1. Pengembangan durian Wonosalam meliputi keuntungan yang diperoleh petani Potensi durian yang melimpah dimusim durian selama 6 bulam dalam setahun. Juga acara wisata kenduri durian yang mebdapat antusias dari masyarakat banyak terutama dari luar kota jombang.

2. Berdasarkan hasil analisis faktor internal dan analisis faktor eksternal di identifikasikan, Kekuatan (.keindahan dan lingkungan alam yang sejuk di lereng gunung Anjasmoro, wisata petik Durian Wonosalam/kampung durian, adanya wisata 
Website : http://agritek.unmermadiun.ac.id/index.php/agritek

kuliner khasWonosalam (Kolak ketan durian yang terkenal legit), Diadakannya wisata kenduri Durian tiap tahun yang banyak menarik pengunjung, tumbuhnya kegiatan ekonomi kreatif masyarakat setempat.untuk meningkatkan pendapatan, lokasi yang strategis tidak terlalu jauh dari kota, sikap masyarakat yang ramah dan mendukung wisata, banyaknya destinasi wisata lain di daerah Wonosalam (air terjun, Goa goa, Makam, Agrowisata (Pangklungan, gunung Kuncung dll, penanganan pasca panen durian : sortasi dan grading, olahan jenang durian, pengemasan buah durian dengan plastik mika) Penanganan pasca panen durian : sortasi dan grading, olahan jenang durian, pengemasan buah durian dengan plastik mika), pemanfaatan limbah durian : kulit durian sebagai bahan baku briket, isi durian untuk bahan campuran tempe dan penstabil es krim susu), Kelemahan (Sarana dan prasarana yang kurang memadai.(Jalan yang kurang lebar dan kurangnya area parkir), kurangnya layanan informasi kepariwisataan, pengelolaan dan pelaku objek wisata belum maksimal),.

3. Peluang (Adanya kunjungan banyak wisatawan, letak strategis terhadap objek wisata lain, adanya kepastian hukum terbukti sebagai daerah wisata, adanya kebijakan pemda, adanya kecenderungan penerapan konsep multi fungsi lahan pertanian, sebagai areal produksi pertanian dan objek wisata Lahan pertanian yang unik berpeluang besar untuk di multifungsikan, kebutuhan akan destinasi wisata alternatif, terjalinnya kerjasama pemerintah, investor, dan masyarakat, otonomi daerah yang diberlakukan pemerintah, adanya promosi wisata lewat media, nilai budaya masyarakat setempat telah mengakar di masyarakat seperti gotong royong, kepercayaan, bahasa, adat istiadat, dan lain sebagainya) dan Ancama (persaingan dengan daerah lain dalam pengembangan desa wisata.(Kenduri Salak Di Wonosalam dan kediri), berubahnya pola pikir dan perilaku masyarakat, adanya pedagang dari luar Wonosalam, adanya penduduk pendatang).

4. Berdasarkan kesimpulan dari matriks SWOT, maka prioritas yang dapat dilakukan adalah Strategi pengembangan agrowisata wisata dengan mempertahankan berbagai daya tarik wisata yang ada dan strategi pengembangan dengan meningkatkan promosi ke pihak pihak terkait dan ke daerah luar baik melalui seminar, pameran ataupun memanfaatkan perkembangan teknologi,

5. Berdasarkan matrik qspm nilai daya tarik tertinggi dengan jumlah nilai TAS tertinggi 6,164 terdapat pada strategi I (mempertahankan daya wisata yang ada dan meningkatkan promosi ke pihak pihak terkait dan ke daerah luar dengan melalui seminar seminar atau memanfaatkan perkembangan teknologi) dan nilai daya tarik tertinggi kedua terdapat pada strategi II dengan jumlah nilai TAS 5,817, nilai daya tarik tertinggi ketiga pada strategi IV dengan jumlah nilai TAS 5,107 dan strategi III dengan nilai daya tarik terendah dengan jumlah nilai TAS 4,956.

\section{Saran}

1. Dalam pengembangan agrowisata durian Wonosalam perlu penataan kembali infrastruktur (pelebaran jalan, area parkir, rest area, pertokoan (food center dan handicraf) dan juga penataan pasar buah serta perlu adanya penambahan kebun petik durian lokal dan kebun petik buah durian Bido yang selama ini menjadi iconnya Wonosalam.

2. Dalam pengelolaan agrowisata durian Wonosalam perlu kebijakan pengelolaan yang tepat dan terarah, termasuk di dalamnya petani pemilik lahan sebagai pengelola. Agar petani tidak semata-mata hanya dijadikan objek melainkan sebagai subjek.

3. Perlu adanya penelitian analisa pendapatan usaha tani dan sensus kepemilikan buah durian pada rumah tangga petani khususnya di desa Wonosalam

\section{DAFTAR PUSTAKA}

Awan, S.A., Saeed, A.F., dan Zhuan F. 2016. TheProspects of AgritourismDevelopmentinChina Journal of Economics and Sustainable DevelopmentVol.7, No.5, 2016

Bachtiar, A., R., Windia, W., dan Sri Astiti, N.,W. 2015. Persepsi Masyarakat dan Strategi Pengembangan Agrowisata Salak Di desa Sibetan Kecamatan Bebandem Kabupaten Karangasem Bali. Jurnal Managemen Agribisnis. Volume 4 No 1 Mei 2016

David, Fred R. 2010. Manajemen Strategis. Ed ke-12. Sunardi D, penerjemah. Jakarta: Salemba Empat Terjemahan dari : Strategic Management, 12th ed.

Fretes, R.,A., Santoso, P., B., Soenoko, R., dan Astuty, M. 2013. Strategi Perencanaan dan Pengembangan Industri Pariwisata dengan Metode SWOT dan QSPM. (Studi Kasus di Kecmatan Leitimur Selatan Kota Ambon). Jurnal Rekayasa Mesin. Volume 4 No 2 Tahun 2013.

Hermawan, Hary. 2016. Dampak Pengembangan Desa Wisata Nglanggeran Terhadap Ekonomi Masyarakat Lokal. Jurnal Pariwisata, Vol 3, No 1, pp 105117....... 2016.

Mappigau, Palmarudi \& Esso, A. Sawe Ri. 2011. Analisis Strategi Pemasaran Telur pada Peternakan Ayam Ras Skala Besar di Kabupaten Sidrap. Jurnal. Fakultas Peternakan Universitas Hasanuddin.

Martaleni. 2011. Pertumbuhan Pariwisata Global: Tantangan untuk Pemasaran Daerah Tujuan Wisata (DTW). Jurnal Manajemen Teori dan Terapan 4(2): 18-19. Pemkab Jombang. 2018. Kecamatan Wonosalam Data Umum.

Prastiti, R. A. 2012. Strategi Pengembangan Agribisnis Sapi Potong di Kabupaten Blora. e-jurnal Agrista. Program Studi Agribisnis. Fakultas Pertanian. Universitas Sebelas Maret. Surakarta.

Rangkuti, F. 2015. Analisis SWOT : Teknik Membedah Kasus Bisnis Cara Perhitungan Bobot, Rating, dan OCAI. Jakarta: Penebit PT.Gramedia Pustaka Utama.

Rianawati, R. 2013. Strategi Pengembangan Agrowisata Perkebunan Gunung Mas PTPN VIII (Studi Kasus Di Unit Usaha Perkebunan Gunung Mas PTPN VIII Kecamatan Cisarua, Kabupaten Bogor, Propinsi Jawa Barat. Agric. Sci. J. Volume 1 (4) : 17-23 2014.

Yahya, Arief. 2015. Sambutan Menteri Pariwisata R.I. Pada Peringatan World Tourism Day dan Hari Kepariwisataan Nasional. Tersedia (http://kemenpar.go.id, diakses 26 September 2017). 